\title{
Simulation of Plant-Water Relations and Photosynthesis of Greenhouse Crops
}

\author{
LEO F.M. MARCELIS* \\ Department of Theoretical Production Ecology, Agricultural University Wageningen, \\ P.O. Box 430, 6700 AK Wageningen (The Netherlands)
}

\begin{abstract}
Marcelis, L.F.M., 1989. Simulation of plant-water relations and photosynthesis of greenhouse crops. Scientia Hortic., 41: 9-18.

An explanatory simulation model was developed to simulate the diurnal course of plant-water relations and their effects on the photosynthesis of greenhouse crops. The simulated effects of global radiation on plant-water relationships and photosynthesis are shown. Measurements of transpiration of a tomato crop (cultivar 'Turbo') showed that daily totals as well as the diurnal course of transpiration on a short-time basis were simulated satisfactorily.
\end{abstract}

Keywords: photosynthesis; plant-water relations; simulation model; tomato; transpiration.

\section{INTRODUCTION}

Existing simulation models for water and carbon relations of plants, like BACROS and PHOTON (De Wit, 1978), do not consider crops in a greenhouse. The model SUCROS (Penning de Vries and van Laar, 1982; Spitters et al., 1989) does not consider plant-water relations at all. Stanghellini (1987) developed a descriptive model for transpiration of greenhouse crops, but photosynthesis, water uptake and water status of the plants were not taken into account. Therefore a new explanatory simulation model was designed to simulate the diurnal course of plant-water relations and their effects on the photosynthesis of greenhouse crops.

The model has been based on the models PHOTON (De Wit, 1978) and MICROWEATHER (Goudriaan, 1977) for plant-water relationships and radiation climate, but uses a more efficient integration routine (Goudriaan, 1986) to calculate canopy totals. The transpiration, water uptake, water content and

*Present address: Centre for Agrobiological Research, P.O. Box 14, 6700 AA Wageningen, The Netherlands. 
water potential of the crop are considered as the main characteristics of the plant-water relationships. By use of the model, the effects of factors like global radiation, air humidity, air temperature, heating pipes, temperature of the greenhouse roof, water potential of the root medium, stomata and leaf area index on plant-water relationships and photosynthesis can be studied during a day.

\section{MATERIALS AND METHODS}

Experimental set-up. - For the measurement of transpiration, a tomato crop (Lycopersicon lycopersicum cultivar 'Turbo') was grown on rockwool mats in a Venlo-type greenhouse at a density of 2 plants per $\mathrm{m}^{2}$. The leaf area index of the crop was $\sim 2 \mathrm{~m}^{2}$ leaf per $\mathrm{m}^{2}$ ground. The minimum temperature was $15^{\circ} \mathrm{C}$ and the maximum $30^{\circ} \mathrm{C}$. The water potential of the root medium was -1 bar. The transpiration of four plants was measured by a lysimeter (Meijer et al., 1985 ) which was placed in the centre of the greenhouse.

Every $5 \mathrm{~min}$, transpiration, global radiation inside the greenhouse, vapour pressure deficit of the air, and the temperatures of the air, of the heating pipes and of the greenhouse roof were recorded by a datalogger.

\section{Theory}

Description of the model. - A simplified relational diagram of the model is presented in Fig. 1. The water content of the plant increases by water uptake by the roots and decreases by transpiration. Photosynthesis is assumed to have no effect on the plant-water relations, which influence photosynthesis via stomatal conductance and leaf temperature.

An almost linear relationship between the water content and water potential of the plant has often been observed (Slatyer, 1967; Burrows and Milthorpe, 1976; Bebhoudian, 1977). Therefore a linear relationship is assumed in the model

$\psi=-75 \times\left(1-\theta / \theta_{\max }\right)$

where $\psi=$ water potential of the plant (bar); $\theta=$ water content of the plant (g $\mathrm{m}^{-2}$, integral of water uptake minus transpiration); $\theta_{\max }=$ maximal water content of the plant $\left(2700 \mathrm{~g} \mathrm{~m}^{-2}\right.$, based on measurements of the fresh weight of tomato plants).

Only one water potential and one water content is calculated for the total plant. To simulate the water potential and water content of different plant parts (leaves), a greater knowledge of internal hydraulic resistances is necessary. If these resistances are small, the calculation of one water potential and one water content for the total plant is a good estimate of the plant water status. 


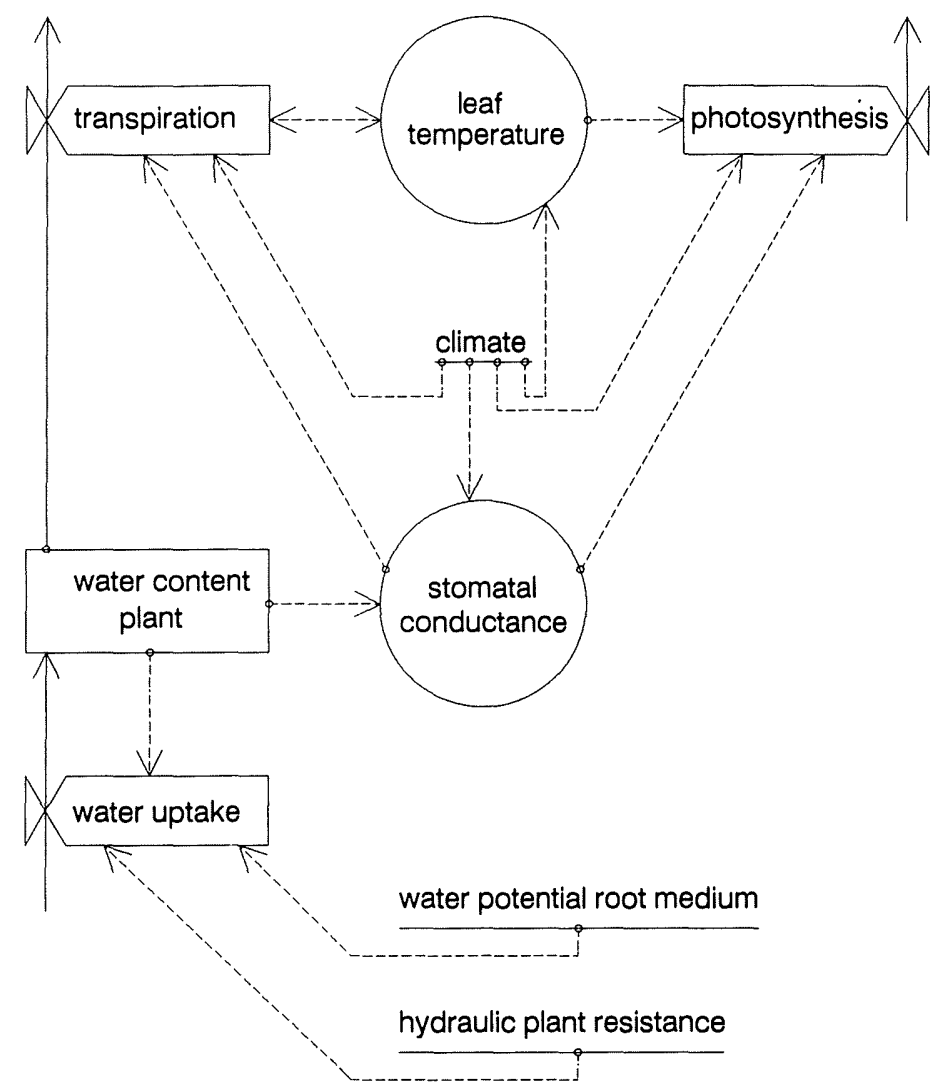

Fig. 1. A simplified relational diagram of the model.

Stomatal conductance. - The simulated stomatal conductance is only influenced by the light intensity and water potential of the plant.

$\mathrm{Up}$ to a photosynthetically active radiation of $50 \mathrm{~W} \mathrm{~m}^{-2}$ (or $100 \mathrm{~W} \mathrm{~m}^{-2}$ global radiation), the simulated stomatal conductance increases linearly with the radiation (Fig. 2a), which seems to be in accordance with the results of Bebhoudian (1977), Hicklenton and Joliffe $(1978,1980)$ and Stanghellini (1987).

The stomata of crops grown in a greenhouse are often more sensitive to the plant water potential (water content) than field-grown crops (Burrows and Milthorpe, 1976). Following De Wit (1978), a linear relationship between water potential and stomatal conductance is assumed (Fig. 2b). At any time, the simulated stomatal conductance is taken to be the minimum of the calculations based on global radiation and water potential.

The stomatal conductance of many crops decreases with increasing $\mathrm{CO}_{2}$ concentration (Burrows and Milthorpe, 1976; Raschke, 1979; Jarvis and Morri- 

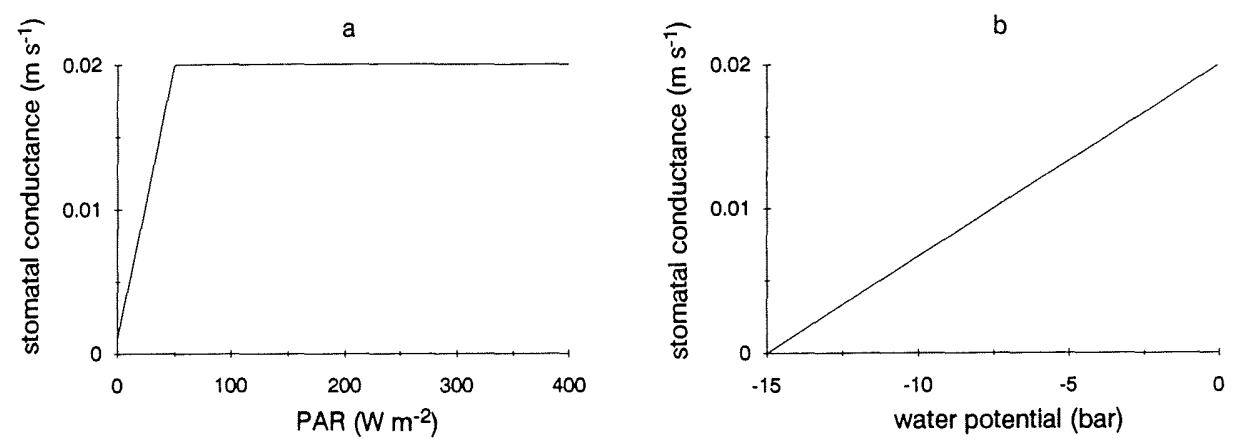

Fig. 2. Simulated stomatal conductance as a function of (a) photosynthetically active radiation $(\mathrm{PAR})$ and $(\mathrm{b})$ water potential of the plant.

son, 1981). However, the stomata of greenhouse crops, which are grown with an ample supply of water, seem to be less responsive to the $\mathrm{CO}_{2}$ concentration (Raschke, 1974; De Wit, 1978; Stanghellini, 1987). Therefore no effect of the $\mathrm{CO}_{2}$ concentration on stomatal conductance is incorporated in the model.

In the model, the leaf temperature and vapour pressure deficit of the air have no direct effect on the stomatal conductance. However, by affecting transpiration, which influences the plant water potential, they can indirectly influence stomatal conductance.

Water uptake by the roots. - The calculation of water uptake is mainly based on the model of Fiscus et al. (1983). Water uptake is primarily governed by the difference between the water potential of the plant and the root medium, but uptake is also enhanced by the osmotic potential of the xylem sap. The water uptake rate is calculated as follows

$J_{\mathrm{v}}=\left(\Delta \psi+-\psi_{\pi}\right) \times L$

where $J_{\mathrm{v}}=$ water uptake rate $\left(\mathrm{g} \mathrm{m}^{-2} \mathrm{~s}^{-1}\right) ; \Delta \psi=$ difference between the water potential of the plant and the root medium (bar); $L=$ hydraulic plant conductance $\left(0.006 \mathrm{~g} \mathrm{bar}^{-1} \mathrm{~m}^{-2} \mathrm{~s}^{-1}\right.$, estimated from the data of Barrs, 1973).

$\psi_{\pi}=-R \times T \times J_{\mathrm{s}} / J_{\mathrm{v}}$

where $\psi_{\pi}=$ osmotic potential of the xylem sap (bar); $R=$ gas constant (8.314 $\left.\mathrm{J} \mathrm{mol}^{-1} \mathrm{~K}^{-1}\right) ; T=$ absolute temperature $(\mathrm{K}) ; J_{\mathrm{s}}=$ solute uptake rate $\left(2.510^{-6}\right.$ $\mathrm{mol} \mathrm{m}{ }^{-2} \mathrm{~s}^{-1}$, estimated from data on solute uptake per root fresh weight (Veen, 1989) times the measured root fresh weight of tomato plants).

These formulae show that at a high rate of water uptake the effect of the osmotic potential of the xylem sap is negligible. However, at low rates this osmotic potential can have a great effect on water uptake and can be considered as the root pressure. Knowledge of the hydraulic resistance of (greenhouse) crops is minimal, but it can have a strong effect on water uptake. 
Transpiration. - Leaf transpiration is calculated at three depths in the canopy for sunlit and shaded leaves. Using the Gaussian integration method (Goudriaan, 1986), the transpiration of the total canopy is obtained. The calculation of leaf transpiration is based on the Penman-Monteith equation. For this calculation, the following climate data are needed: visible; near infra red and thermal (from and to heating pipes, greenhouse roof and soil) radiation; vapour pressure deficit of the air; air temperature. Moreover, values of the stomatal and boundary layer conductance of the leaf are required. Leaf temperature is simultaneously calculated.

Photosynthesis. - According to the SUCROS model (Spitters et al., 1989), photosynthesis is simulated at the leaf level and subsequently integrated to photosynthesis of the canopy (like transpiration). As transpiration influences the leaf temperature and water potential affects the stomatal conductance, photosynthesis is influenced by the plant-water relations.

\section{RESULTS AND DISCUSSION}

Sensitivity analysis - simulated effects of global radiation. - The model showed that global radiation is one of the main factors controlling plant-water relations and photosynthesis. Transpiration increased non-linearly with increasing global radiation (Fig. 3a) because of light-induced opening of the stomata (Fig. 3b). At higher radiation levels, the effect of radiation on transpiration was reduced because of some stomatal closure. The shape of the transpirationradiation curve corresponds to the results on tomato of Drews (1984), Nagaoka et al. (1984) and Stanghellini (1987). In accordance with our simulation, Bebhoudian (1977) measured an increase in stomatal resistance at high radiation levels for cucumber and sweet pepper. For tomato, however, this was not found, perhaps because the experiment on this species was not as extended as for cucumber and sweet pepper, and because it concerned only measurements in the morning. At high radiation levels, the simulated water potential of the plants decreased as a result of high transpiration rates (Fig. 3c), which agrees with measurements of Smart and Barrs (1973), Reicosky et al. (1975) and Bebhoudian (1977) on peaches, prunes, citrus, grapes, maize and tomato. At a low radiation level the leaves were colder than the air, since the absorbed radiation was less than the energy loss by transpiration (latent heat) (Fig. 3d and e). At higher radiation levels the absorbed radiation exceeded the latent heat, resulting in an increased leaf temperature, which is in accordance with the results of Stanghellini (1987). From Fig. 3e it can be deduced that the latent heat, as a percentage of global radiation energy, decreased with increasing radiation.

At low radiation levels gross photosynthesis was strongly enhanced by an increment in radiation (Fig. $3 \mathrm{f}$ ). With increasing radiation this effect dimin- 

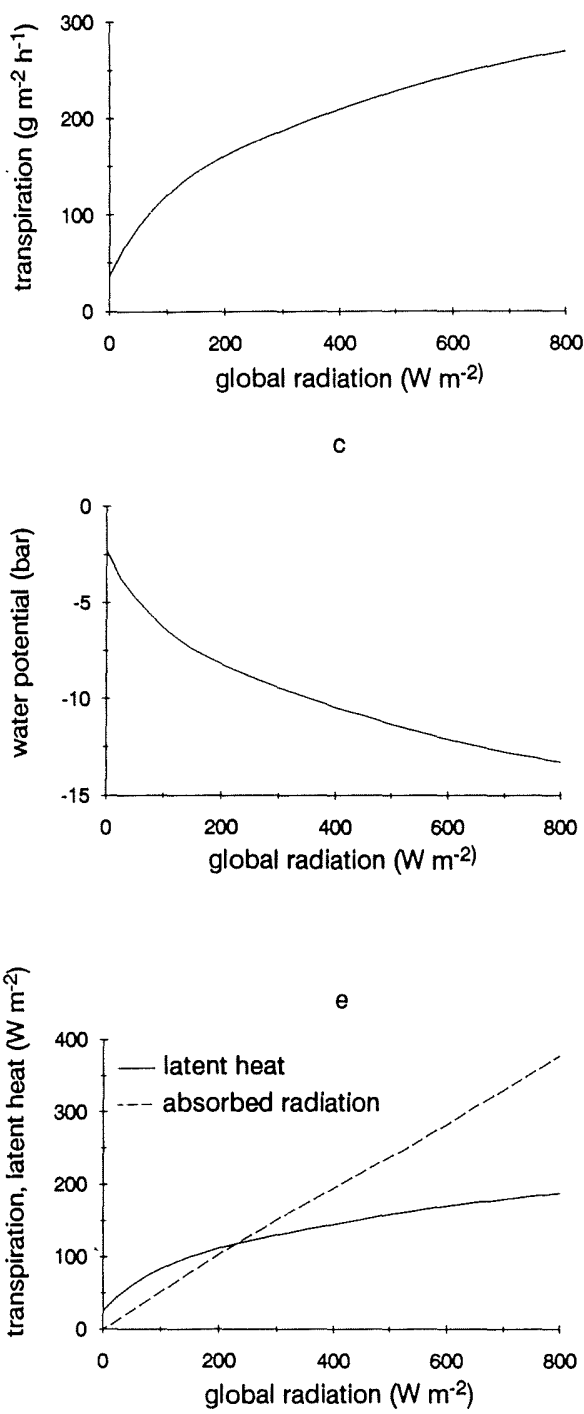

b

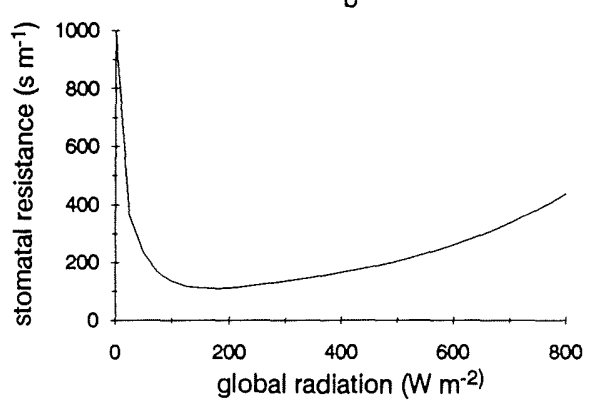

d
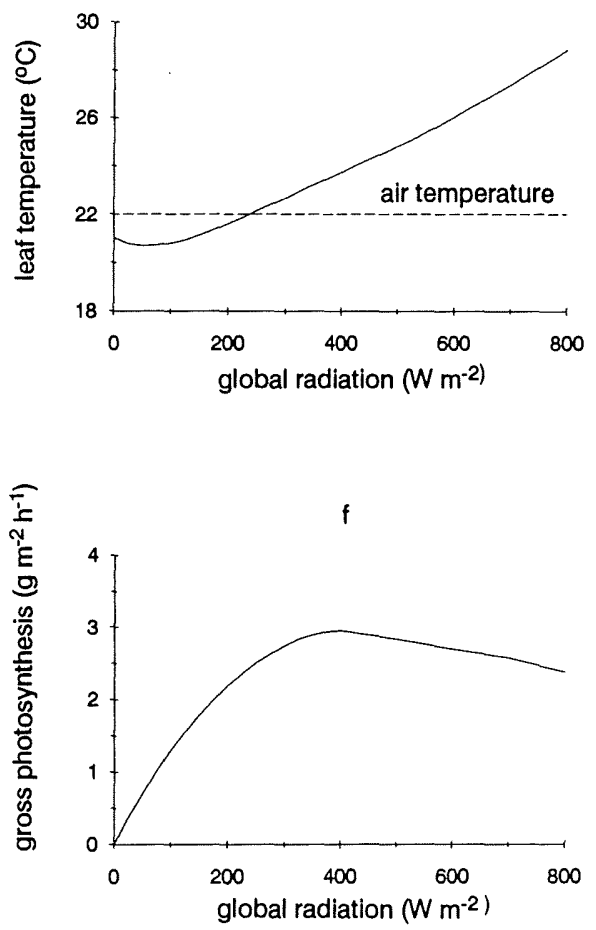

Fig. 3. Simulated influence of global radiation inside a greenhouse on (a) transpiration, (b) stomatal resistance, (c) water potential of the plant, (d) leaf temperature, (e) absorbed global radiation and latent heat, (f) gross photosynthesis.

ished. At high radiation levels gross photosynthesis even declined, because of an increased stomatal resistance. A decrease in the photosynthesis of greenhouse crops, grown with an ample supply of water, at high radiation levels was also observed by Bebhoudian (1977) for cucumber and sweet pepper, but not for tomato. 
Validation of the simulated transpiration. - Simulated transpiration was compared with actual measurements on a tomato crop during 9 days. Input data for the simulation model were the measured global radiation inside the greenhouse, vapour pressure deficit of the air and the temperature of the air, of the heating pipes and of the greenhouse roof. On most days, the simulation of daily totals corresponded well to the measurements (Table 1). Daily totals as well as the diurnal course of transpiration on a short-term basis were simulated well (Fig. 4).

Some discrepancies between simulation and measurement could be the result of a bad simulation of stomatal resistance. Late in the afternoon transpiration was often overestimated by the model (Fig. 4b), especially on days with high transpiration rates. When the transpiration rate was high, simulated stomatal resistance increased during the day because of a declining water potential of the plant. Late in the afternoon transpiration decreased and the simulated water potential increased again. As a result the simulated stomatal resistance diminished. Possibly the simulated effect of increasing water potential on stomatal resistance should have been delayed by $0.5-2 \mathrm{~h}$. This time lag might be proportional to the minimal water potential reached during the day, as indicated by Hsiao (1973).

On those days when late in the afternoon transpiration was overestimated by the model, the vapour pressure deficit was still quite high while simulated stomatal resistance decreased. A high vapour pressure deficit can increase stomatal resistance (Burrows and Milthorpe, 1976; Raschke, 1979; Stanghellini, 1987). In the model, vapour pressure deficit has only an indirect effect on stomatal resistance, by affecting transpiration and water potential. A direct effect on stomatal resistance might improve the simulation of transpiration.

TABLE 1

Daily totals of measured and simulated transpiration of a tomato crop

\begin{tabular}{llll}
\hline Day & $\begin{array}{l}\text { Measurement } \\
\left(\mathrm{g} \mathrm{m}^{-2}\right)\end{array}$ & $\begin{array}{l}\text { Simulation } \\
\left(\mathrm{g} \mathrm{m}^{-2}\right)\end{array}$ & $\begin{array}{l}\text { Difference } \\
(\%)\end{array}$ \\
\hline 26 April & 1109 & 900 & -19 \\
27 April & 1217 & 1038 & -15 \\
30 April & 1816 & 1941 & +7 \\
1 May & 1933 & 2234 & +16 \\
2 May & 2251 & 2568 & +14 \\
3 May & 2111 & 2103 & 0 \\
12 May & 2039 & 1996 & -2 \\
13 May & 1770 & 1798 & +2 \\
14 May & 1792 & 1934 & +8 \\
\hline
\end{tabular}




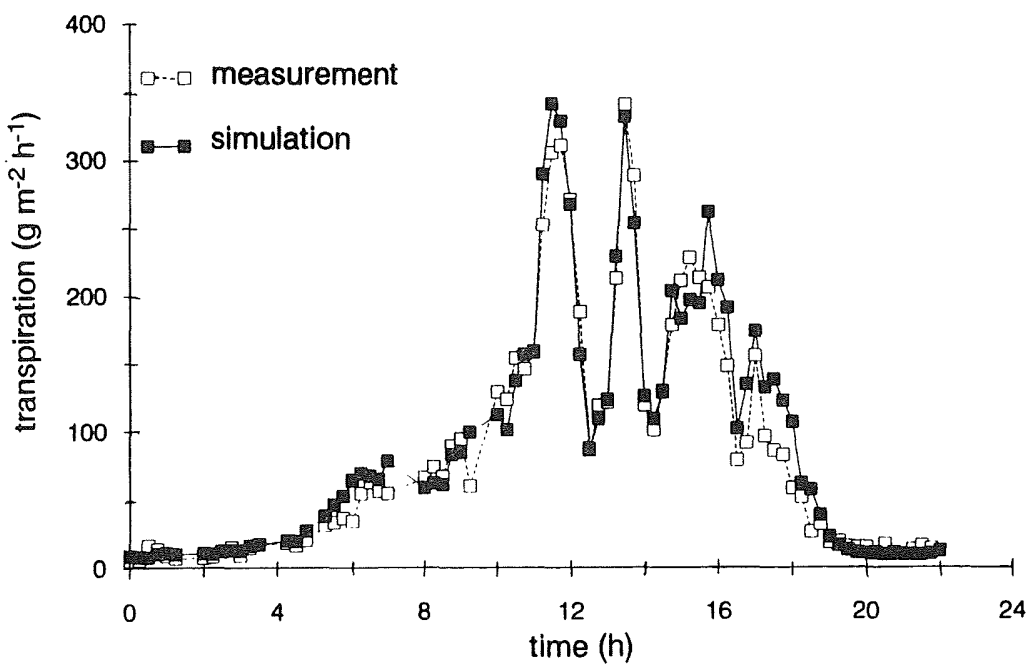

b

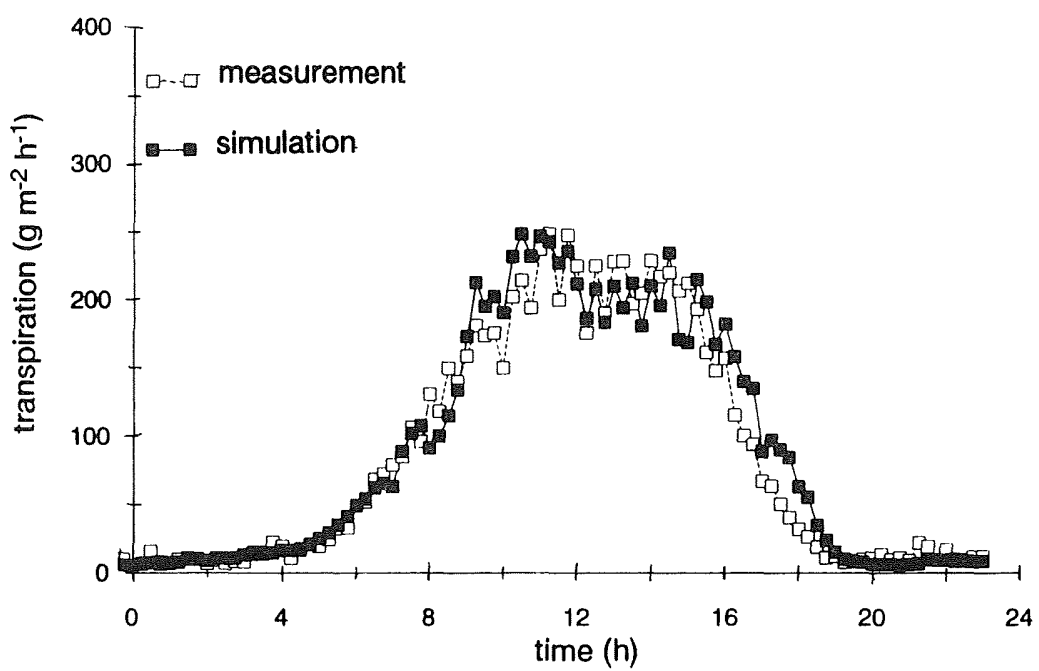

Fig. 4. Measured and simulated transpiration of a tomato crop. (a) 14 May and (b) average of 9 days.

\section{CONCLUSIONS}

The simulation model provides a useful tool to investigate the effects of climate factors like global radiation on plant-water relations. Also, the effects of the plant-water relations on photosynthesis can be studied. The model gives a good prediction of the diurnal course of transpiration of a tomato crop. 


\section{ACKNOWLEDGEMENTS}

I am very grateful to Ir. G.T. Bruggink for providing the measured data on climate and transpiration of the tomato crop. I wish to thank Prof. H. Challa, Dr. H.M. Dekhuijzen, Ir. J.G. Gijzen, Dr. J. Goudriaan, Prof. R. Rabbinge, Ir. P.A.C.M. van de Sanden and Dr. H.C.M. de Stigter for their invaluable help and advice.

\section{REFERENCES}

Barrs, H.D., 1973. Controlled environment studies of the effects of variable atmospheric water stress on photosynthesis, transpiration and water status of Zea mays L. and other species. Proceedings of a Symposium on Plant Response to Climatic Factors, UNESCO, Uppsala, 249258.

Bebhoudian, M.H., 1977. Water relations of cucumber, tomato and sweet pepper. Meded. LH 776, Wageningen, 85 pp.

Burrows, F.J. and Milthorpe, F.L., 1976. Stomatal conductance in gas exchange control. In: T.T. Kozlowski (Editor), Water Deficits and Plant Growth. IV. Academic Press, New York, pp. 103-153.

De Wit, C.T., 1978. Simulation of Assimilation, Respiration and Transpiration of Crops. Pudoc, Wageningen, $141 \mathrm{pp}$.

Drews, M., 1984. Der Einfluss einiger Wachstumfaktoren auf den Wasserhaushalt der Gewaechshaustomate. Arch. Gartenbau, 32: 103-114.

Fiscus, E.L., Klute, A. and Kaufmann, M.R., 1983. An interpretation of some whole plant water transport phenomena. Plant Physiol., 71: 810-817.

Goudriaan, J., 1977. Crop Micrometeorology: A Simulation Study. Pudoc, Wageningen, 249 pp.

Goudriaan, J., 1986. A simple and fast numerical method for the computation of daily totals of crop photosynthesis. Agric. For. Meteorol., 38: 249-254.

Hicklenton, P.R. and Jolliffe, P.A., 1978. Effects of greenhouse $\mathrm{CO}_{2}$ enrichment on the yield and photosynthetic physiology of tomato plants. Can. J. Plant Sci., 58: 801-817.

Hicklenton, P.R. and Jolliffe, P.A., 1980. Alterations in the physiology of $\mathrm{CO}_{2}$ exchange in tomato plants grown in $\mathrm{CO}_{2}$-enriched atmospheres. Can. J. Bot., 58: 2181-2189.

Hsiao, T.C., 1973. Plant responses to water stress. Ann. Rev. Plant Physiol., 24: 519-570.

Jarvis, P.G. and Morison, J.I.L., 1981. The control of transpiration and photosynthesis by the stomata. In: P.G. Jarvis and T.A. Mansfield (Editors), Stomatal Physiology. Soc. Exp. Biol. Semin. Ser., 8: 247-279.

Meijer, J., Bot, G.P.A., Stanghellini, C. and Udink ten Cate, A.J., 1985. Development and application of a sensitive, high precision weighing lysimeter for use in greenhouses. J. Agric. Eng. Res., 32: 321-336.

Nagaoka, M., Takahashi, K. and Arai, K., 1984. Effect of environmental factors on photosynthesis and transpiration of tomato and cucumber plants. Bull. Veg. Orn. Crops Res. Stn. Jpn., A12: 98-117.

Penning de Vries, F.W.T. and van Laar, H.H. (Editors), 1982. Simulation of Plant Growth and Production. Pudoc, Wageningen, $308 \mathrm{pp}$.

Raschke, K., 1974. Abscisic acid sensitizes stomata to $\mathrm{CO}_{2}$ in leaves Xanthium strumarium L. Proceedings of the 8th International Conference on Plant Growth Substances, Hirokawa Publishing Co., Tokyo, pp. 1151-1158. 
Raschke, K., 1979. Movement of stomata. In: W. Haupt and M.E. Feinleib (Editors), Encyclopedia of Plant Physiology, new series. Springer, Berlin, 7: 383-441.

Reicosky, D.C., Campbell, R.B. and Doty, C.W., 1975. Diurnal fluctuation of leaf-water potential of corn as influenced by soil matric potential and microclimate. Agron. J., 67: 380-385.

Slatyer, R.O., 1967. Plant-water relationships. Academic Press, London, 366 pp.

Smart, R.E. and Barrs, H.D., 1973. The effect of environment and irrigation interval on leaf water potential of four horticultural species. Agric. Meteorol., 12: 337-346.

Spitters, C.J.T., Keulen, H. and van Kraalingen, D.W.G., 1989. A simple and universal crop growth simulator: SUCROS 87. In: R. Rabbinge, S.A. Ward and H.H. van Laar (Editors), Simulation and Systems Management in Crop Protection. Pudoc, Wageningen, in press.

Stanghellini, C., 1987. Transpiration of greenhouse crops. An aid to climate management. $\mathrm{PhD}$. thesis, Agricultural University, Wageningen, $150 \mathrm{pp}$.

Veen, B.W., 1989. Influence of oxygen deficiency on growth and function of plant roots. In: B.C. Loughman, O.H. Gasparikova and J. Kolek (Editors), Structural and Functional Aspects of Transport in Roots. Kluwer Acad. Publ., Dordrecht, pp. 223-229. 